\title{
Effect of suckling and adrenergic stimulation on peripheral deiodination in lactating rats: differential expression of type 1 deiodinase mRNA forms
}

\author{
C Aceves and R Rojas-Huidobro \\ Departamento de Neurobiología Celular y Molecular, Centro de Neurobiología, Universidad Nacional Autonoma de Mexico, Campus Juriquilla, \\ Querétaro, México \\ (Requests for offprints should be addressed to C Aceves, Departamento de Neurobiología Celular y Molecular, Centro de Neurobiología, \\ UNAM-Juriquilla, Apartado Postal 1-1141, Querétaro, Querétaro 76001, México; Email: caracev@servidor.unam.mx)
}

\begin{abstract}
Previous works led us to propose that peripheral iodothyronine deiodination is mainly regulated by the reciprocal interaction between the thyroid and the sympathetic nervous system (SNS). In this study, we analyzed the role suckling exerts, through SNS activation, upon deiodination of thyronines in liver, heart, brown adipose tissue and mammary gland during lactation. Our results showed that resuckling causes a concurrent stimulatory response on deiodinase type 1 (D1) in heart and mammary gland, but
\end{abstract}

not in liver and brown adipose tissue. The stimulatory response was mimicked by norepinephrine and by the $\beta$-adrenergic agonist isoproterenol, through the overexpression of the large form of D1 mRNA. These results suggested that, during lactation, peripheral thyronine deiodination is co-ordinated by the SNS, and suckling is a major modulatory influence.

Journal of Endocrinology (2001) 171, 533-540

\section{Introduction}

In vertebrates, thyroxine (T4), the major hormone produced by the thyroid gland, must be converted by $5^{\prime}$-deiodination $\left(5^{\prime} \mathrm{D}\right)$ into tri-iodothyronine (T3) to exert its control upon several functions; i.e. growth and development, thermogenesis and energetic expenditure (Kohrle 1999). This biotransformation, which takes place in target tissues, is catalyzed by two selenoenzymes called deiodinases type 1 and type 2 (D1 and D2 respectively). D1 is sensitive to inhibition by propylthiouracil (PTU), has a ping-pong catalytic mechanism and is expressed in organs such as liver, kidney, thyroid, heart, pituitary and lactating mammary gland (MG). D2 has a sequential catalytic mechanism, is highly resistant to PTU, and is present in brain, skin, placenta and brown adipose tissue (BAT) (Larsen et al. 1981, Leonard \& Kohrle 1996). Extensive clinical and experimental data indicate that the reciprocal functional relationship between the thyroid and the sympathetic nervous system (SNS) constitutes a critical part of the homeorhetic mechanisms aimed at preserving the organism's metabolic fitness (Aceves et al. 1994, Silva 1996). Lactation is an excellent example of these homeorhetic adjustments and, in terms of peripheral thyronine deiodination, we have shown that (1) despite the hyperphagia present during lactation, the organ-specific adjust- ments in peripheral deiodination resemble those observed in fasted or hypothyroid animals (Valverde-R \& Aceves 1989, Aceves et al. 1994); (2) these adjustments are not modified by overfeeding or by thyroid hormone administration (Aceves et al. 1994); (3) this 'pseudohypothyroidism' is exacerbated when the lactational demand (litter size) is increased (Valverde-R \& Aceves 1989); (4) D1 enzyme is encoded by two messengers that differ in the length of their $3^{\prime}$-untranslated region ( $3^{\prime} U T R$ ), and the expression of the large form is directly correlated to thyroid status (Navarro et al. 1997); (5) MG D1, which is encoded by the short messenger, is positively regulated by suckling through the efferent sympathetic mammary innervation (Aceves et al. 1999a); and (6) this local MG D1 regulation involves segmental mechanisms that, depending on the size of the litter, may allow a differential, gland by gland adjustment of energetic expenditure (Aceves et al. 1999b). These findings add further support to our proposal that, during lactation, deiodination represents a functional intersection of the dyad thyroid-SNS to maintain the elevated energy supply needed by the lactating mammary gland (Aceves et al. 1999b). Thus, the present study was designed to gain further insight into the background of this thyroid-SNS interaction, and to test the hypothesis that suckling, through SNS activation, modulates the homeorhetic adjustments that characterize lactation. 


\section{Materials and Methods}

\section{Reagents}

Non-radioactive thyronines were obtained from Henning Co. (Berlin, Germany). Radiolabeled reverse T3 (rT3; specific activity $1174 \mu \mathrm{Ci} / \mu \mathrm{g}$ ) and $\mathrm{T} 4$ (specific activity $1174 \mu \mathrm{Ci} / \mu \mathrm{g})$ were purchased from New England Nuclear (Boston, MA, USA). Dithiothreitol (DTT) and oxytocin (OT) were obtained from Calbiochem (La Jolla, CA, USA), and norepinephrine (NE) and isoproterenol (ISO) from Sigma Chemical (St Louis, MO, USA). Oligonucleotides were synthesized by GIBCO-BRL (Gaithersburg, MD, USA). All other reagents were of the highest purity commercially available.

\section{Animals}

Virgin (250 g) and primiparous (300 g) Sprague-Dawley rats were housed in individual cages in a room with a $14 \mathrm{~h}$ light:10 h darkness cycle. On postpartum day 1, the size of the litter was adjusted to ten pups per mother and all the experimental procedures were conducted on postpartum day $10 \pm 1$. All animals were fed Purina Lab Chow and tap water ad libitum. Procedures regarding care, administration of treatment and euthanasia of animals were reviewed and approved by the supporting Direccion general de asuntos del personal academico (DGAPA)/UNAM Committee. All animals were killed by decapitation and two samples of liver, heart, BAT and MG of each individual were dissected. One sample of each tissue was immediately frozen on liquid nitrogen and the other sample was homogenized in a guanidine thiocyanate solution.

\section{Enzymatic assay}

Deiodinase activity was determined by a modification of the radiolabeled iodide release method as previously standardized for each tissue (Aceves et al. 1994). All tissues were homogenized in a solution containing $10 \mathrm{mM}$ HEPES $(\mathrm{pH}$ 7.0), 0.32 $\mathrm{M}$ sucrose, $1.0 \mathrm{mM}$ EDTA and $20 \mathrm{mM}$ DTT, and centrifuged at $2800 \mathrm{~g}$ for $30 \mathrm{~min}$ at $4{ }^{\circ} \mathrm{C}$. Assay conditions for tissues containing D1 activity (liver, heart and MG) were $0 \cdot 2-200 \mu \mathrm{g}$ protein, $2 \mathrm{nM}{ }^{125} \mathrm{I}-\mathrm{rT} 3$, $0.5 \mu \mathrm{M}$ non-radiolabeled rT3 and $5 \mathrm{mM}$ DTT. For BAT (which expresses D2 enzyme) the assay was carried out with $200 \mu \mathrm{g}$ protein, $2 \mathrm{nM}{ }^{125} \mathrm{I}-\mathrm{rT} 4$ and $20 \mathrm{mM}$ DTT. After $3 \mathrm{~h}$ of incubation, released acid-soluble radioiodide was isolated by chromatography in Dowex 50W-X2 columns (Bio-Rad, Richmond, CA, USA). Proteins were measured by the Bradford method (Bio-Rad protein assay; Bio-Rad). Results are expressed as fmol or pmol radioiodide released/mg protein $/ \mathrm{h}$.

\section{$R T-P C R$}

D1 or D2 mRNAs were identified by using a previously standardized semi-quantitative PCR procedure in which an amplicon of the structural protein cyclophilin (Cyc) was simultaneously amplified (Aceves et al. 1999a). Briefly, the reverse transcription (RT) reaction was primed with oligo(dT) and subscripted with $5 \mu \mathrm{g}$ total RNA. The PCR reaction was carried out using $5 \mu \mathrm{l} \mathrm{RT}$ mixture and the following primers: for D1, M2s and M6as, for D2, D22s and D26as and for Cyc, Cyc1s and Cyc7as (see Fig. 1). Amplification was carried out for 32 cycles. Each cycle consisted of melting at $94{ }^{\circ} \mathrm{C} \times 45 \mathrm{~s}$, annealing at $52{ }^{\circ} \mathrm{C} \times 45 \mathrm{~s}$, and an extension at $72{ }^{\circ} \mathrm{C} \times 1 \mathrm{~min}$. As a control, a reaction mixture containing an RNA sample with the appropriate oligonucleotide primers, but without the RT, was included in every experiment. The sizes of the resultant PCR fragments were $251 \mathrm{bp}$ for D1, $805 \mathrm{bp}$ for D2 and $521 \mathrm{bp}$ for $\mathrm{Cyc}$, and were resolved on a $2 \%$ agarose gel and visualized using ethidium bromide. The sizes of the bands were confirmed by a restriction digested pUC plasmid (1 kb DNA ladder; GIBCO-BRL). After a Polaroid picture had been taken, the pictures were digitized using a Hewlett Packard Scanner Jet 11CX, and the signals were analyzed by using an editing version of the NIH-image program. Values obtained were normalized according to the Cyc mRNA levels detected in each sample.

\section{3'UTR amplification}

The length of 3'UTR D1 mRNA was assessed by using a previously standardized $3^{\prime}$-rapid amplification cDNA ends (RACE) procedure (Aceves et al. 1999a) and $5 \mu \mathrm{g}$ total RNA from liver, heart and MG. The RT reaction was primed with oligo(dT) containing a terminal specific sequence, AP (see Fig. 1). Amplification was carried out for twenty cycles consisting of melting at $94{ }^{\circ} \mathrm{C} \times 45 \mathrm{~s}$, annealing at $50{ }^{\circ} \mathrm{C} \times 45 \mathrm{~s}$, and an extension at $72{ }^{\circ} \mathrm{C} \times$ $1 \mathrm{~min}$, with $\mathrm{J} 3 \mathrm{~s}$ and UAP oligos (see Fig. 1) and a second tandem of 40 cycles of melting at $94{ }^{\circ} \mathrm{C} \times 45 \mathrm{~s}$, annealing at $52{ }^{\circ} \mathrm{C} \times 45 \mathrm{~s}$, and extension at $72{ }^{\circ} \mathrm{C} \times 1 \mathrm{~min}$ with the same oligos. The resultant PCR fragments were 956 and $506 \mathrm{bp}$ for large and short mRNA forms respectively. To verify the presence of the long form of D1 mRNA in each tissue a PCR amplification was carried out with oligos whose sequence is only present in the $3{ }^{\prime}$-terminal region of the long mRNA form (As and Bas), with a resultant fragment of $136 \mathrm{pb}$ (see Fig. 1). Amplified fragments were electrophoresed on $2 \%$ agarose gel and visualized using ethidium bromide.

\section{Statistical analysis}

Data are expressed as the means \pm S.D. Differences between experimental groups were analyzed using a one-way ANOVA and Tukey's HSD test. Differences with a $P<0.05$ were considered statistically significant.

All experiments had parallel controls, which consisted of intact virgin rats and mothers with continuous suckling. 
A

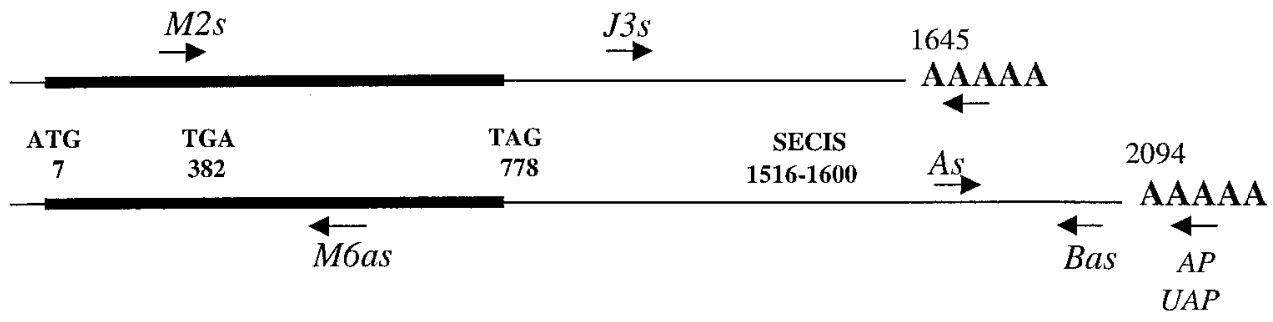

\begin{tabular}{|c|c|c|l|c|}
\hline primer & size & location & \multicolumn{1}{|c|}{ sequence } & purpose \\
\hline M2s & $20-\mathrm{mer}$ & $377-396$ & GCA CCT GAT CTT CAT TTC TT & PCR \\
\hline M6as & $18-\mathrm{mer}$ & $610-627$ & CTG GCT GCT CTG GTT CTG & PCR \\
\hline J3s & $20-\mathrm{mer}$ & $1138-1157$ & GTT TGC CAC TCA TAG ATT CA & RACE \\
\hline As & $20-$ mer & $1693-1712$ & CTG CCG TCT TTT CCG ATA GC & PCR \\
\hline Bas & $20-$ mer & $1809-1829$ & CCC TTC CAC AAC ACT TGA CA & PCR \\
\hline AP & $36-m e r$ & & GTC CAC GCA TCG ACT AGT AT(17) & RT-RACE \\
\hline UAP & $20-$ mer & & GTC CAC GCA TCG ACT AGT AT & RACE \\
\hline
\end{tabular}

\section{B}

\begin{tabular}{|c|c|c|l|c|}
\hline primer & size & location & \multicolumn{1}{|c|}{ sequence } & purpose \\
\hline D22s & $21-\mathrm{mer}$ & $545-565$ & GAG TGC ACA GGA GAC TGA CTG & PCR \\
\hline D26as & $21-\mathrm{mer}$ & $135-1330$ & CTT CTC CAG CCA ACT TCG G AC & PCR \\
\hline Cyc1s & $21-\mathrm{mer}$ & $7-27$ & AGA CGC CGC TGT CTC TTT TCG & PCR \\
\hline Cyc4as & $23-\mathrm{mer}$ & $527-507$ & CCA CAC AGT CGG AGA TGG TGA TC & PCR \\
\hline
\end{tabular}

Figure 1 (A) Schematic representation of two mRNAs of D1 enzyme. Arrows represent the position and direction of the different oligonucleotides used. Exact position, length and sequence are illustrated. (B) The characteristics of oligonucleotides used by D2 and Cyc mRNA amplification. RT, reverse transcriptase.

Whenever the glands were not resuckled by pups, accumulated milk was removed by administration of OT (30 $\mathrm{mU}$; i.p.) $1 \mathrm{~min}$ before they were killed. This procedure ensures that accumulated milk will not act as a dilution factor when tissue proteins are quantified.

\section{Results}

Figure 2 shows the changes exhibited by $5^{\prime} \mathrm{D}$ activity in all groups. Enzymatic values differed between virgin and lactating rats in all tissues analyzed. Lactation was accompanied by significantly higher $5^{\prime} \mathrm{D}$ activity values in heart and MG, and lower activity in liver and BAT. After
$12 \mathrm{~h}$ of non-suckling, the mothers exhibited a significant $(\approx 50 \%)$ decrease in heart and MG D1 activity, whereas in liver and BAT the enzymatic activity remained unchanged. Within the initial 12-h non-suckling interval, resuckling $(4 \mathrm{~h})$ could restore the enzymatic activities to control values in heart and MG. Adrenergic stimulation exerted a differential effect on $5^{\prime} \mathrm{D}$ activities. In virgin animals, NE and ISO administration increased heart D1 and BAT D2 activities. In lactating animals, both NE and ISO elicited a significant $5^{\prime} \mathrm{D}$ stimulatory response in heart and MG, but not in BAT. In contrast, in neither virgin nor lactating animals were these adrenergic agents able to evoke a detectable response in liver D1 activity. As depicted in Fig. 3 these changes in enzyme activity were 

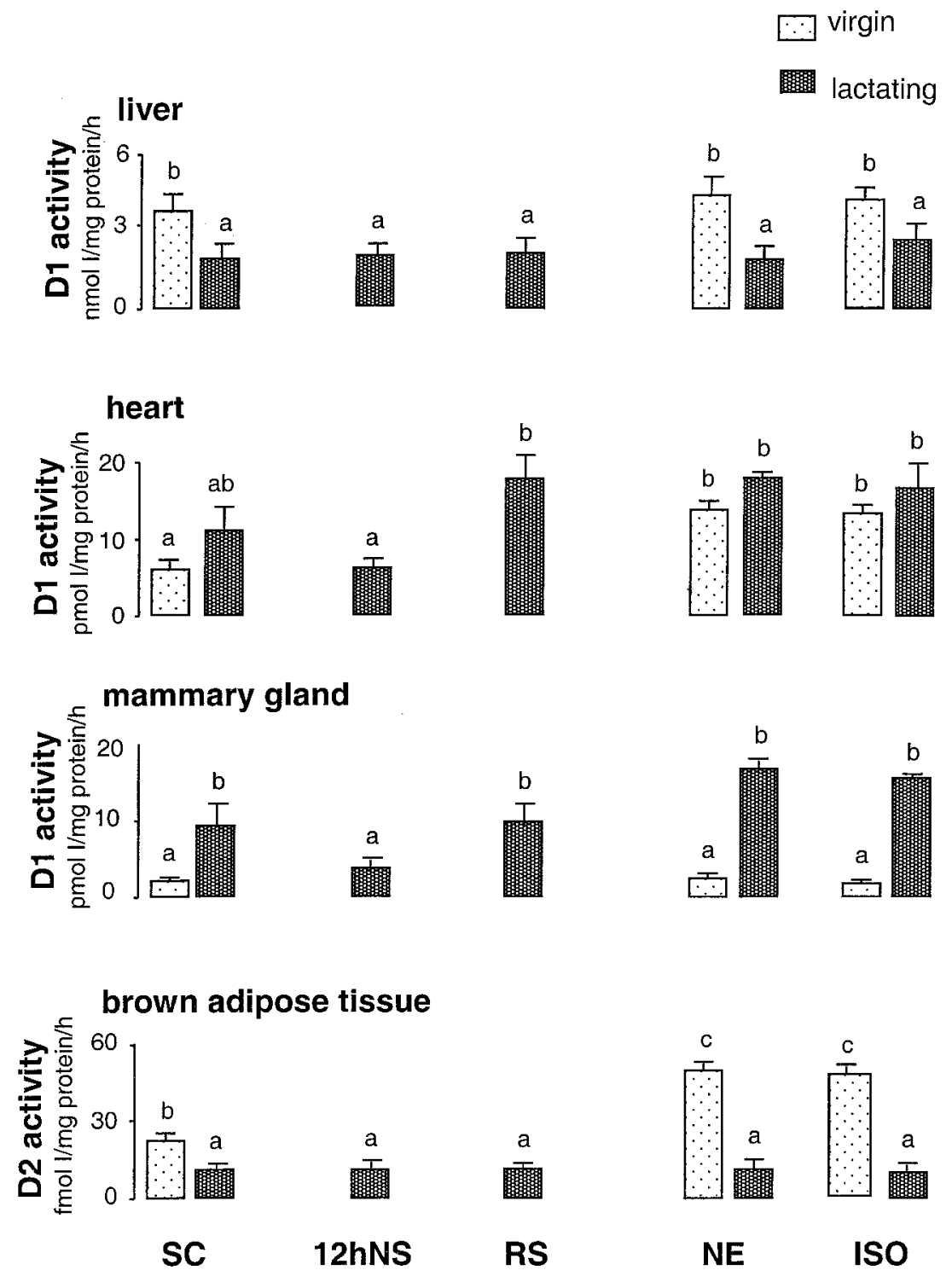

Figure 2 Comparison of $5^{\prime}$ deiodinase (D) activity in different tissues from virgin and lactating rats. Control animals included intact virgin animals and lactating mothers in which suckling was continuous (SC), the rest of the lactating rats were separated from their pups for $12 \mathrm{~h}$. One group was killed after $12 \mathrm{~h}$ of non-suckling ( $12 \mathrm{hNS}$ ), a second group was resuckled by their pups for $15 \mathrm{~min}$ and killed $4 \mathrm{~h}$ later (resuckled group; RS), the last two groups were treated with $40 \mu \mathrm{g} / 100 \mathrm{~g}$ body weight norepinephrine (NE) and $100 \mu \mathrm{g} / 100 \mathrm{~g}$ body weight isoproterenol (ISO) respectively, and killed $4 \mathrm{~h}$ later. Virgin animals received the same doses of both substances. Data are expressed as the means \pm S.D. $(n=6)$. Means with different letters are significantly different $(P<0 \cdot 05)$.

parallel with those exhibited by D1 and D2 mRNAs, thus suggesting that these treatments exert their action at transcriptional level.

The PCR-RACE method was employed to analyze the 3'UTR D1 mRNA from liver, heart and MG. Figure 4 shows that two fragments were amplified from heart and liver cDNAs, indicating the presence of two D1 mRNA forms in these tissues. In previous work, we have amplified and sequenced these fragments and showed that the longer form uses the second polyadenylation site in the $3^{\prime} \mathrm{UTR}$ region of the mRNA (Navarro et al. 1997). A more intense signal was evident for the short fragment than the larger one, suggesting that the short mRNA is more abundant. Nevertheless, it is difficult to interpret the 


\section{Liver}

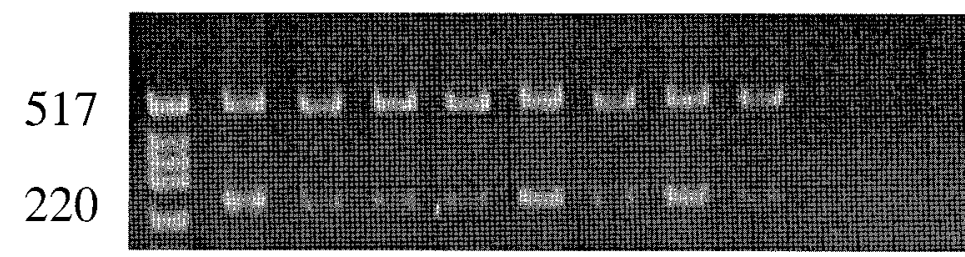

Cyc

D1

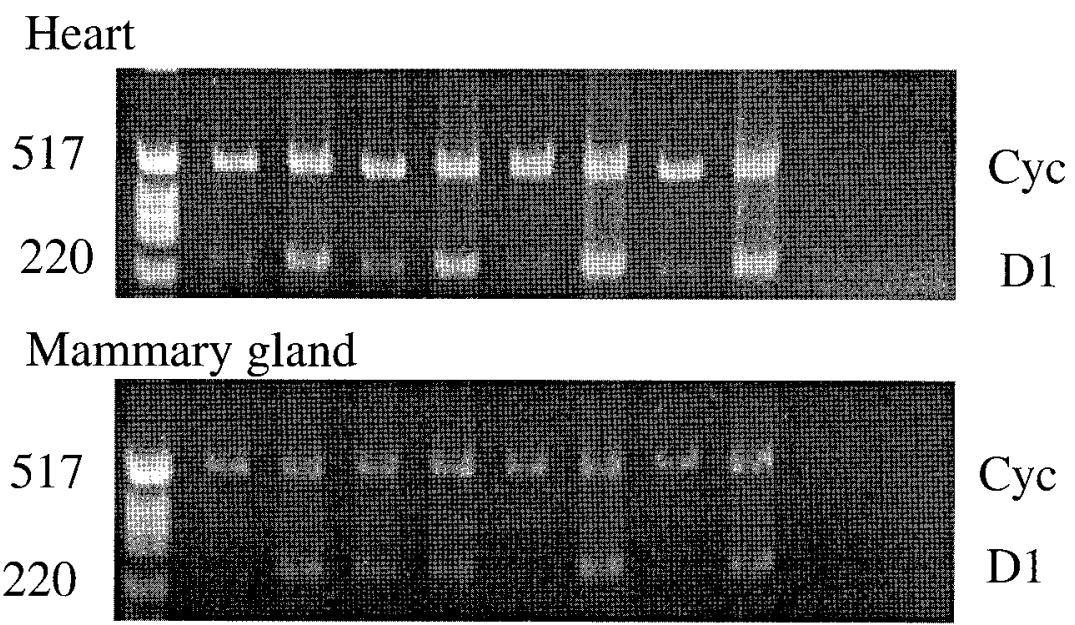

Brown adipose tissue

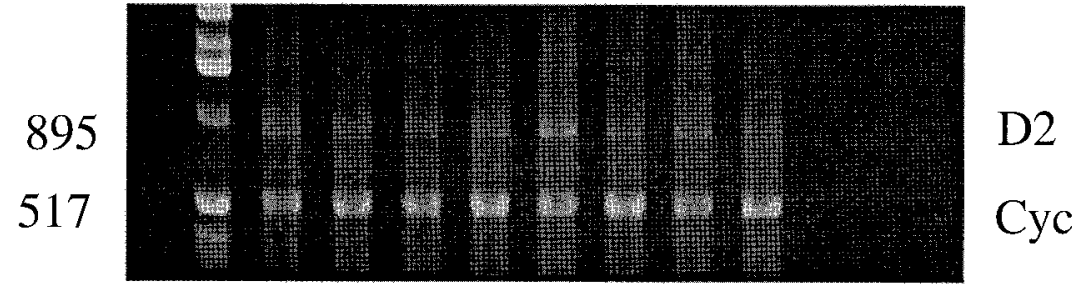

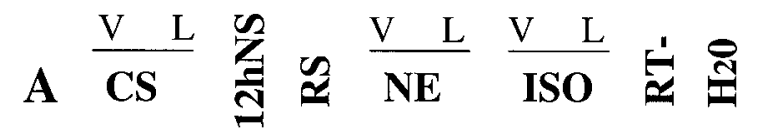

Figure 3 Comparison of mRNAs for 5 'deiodinases in different tissues from virgin $(\mathrm{V})$ and lactating (L) rats. Ethidium bromide-stained gel showing RT-PCR products for D1 (221 bp) and cyclophilin (Cyc) (520 bp) after 40 cycles of amplification. A, ladder; CS, control animals with continuous suckling; $12 \mathrm{hNS}$, mothers whose pups were removed for $12 \mathrm{~h}$; $\mathrm{RS}$, mothers whose pups were resuckled after $12 \mathrm{~h}$ of non-suckling; NE, animals treated with NE; ISO animals treated with ISO; RT - , RNA sample and the appropriate oligonucleotide primers, but without reverse transcriptase; $\mathrm{H}_{2} \mathrm{O}$, water with all the PCR reagents. The experiments were repeated twice with independent RNA samples.

relative quantities of two isoforms considering that a co-amplification took place, and the replication efficiency is dependent on the fragment size (Stolovitzky \& Cacchi 1996). In the case of MG, only the short fragment was evident in lactating animals. When we corroborated the presence of the long mRNA form using PCR amplification for the last portion of the $3^{\prime} \mathrm{UTR}$, fragments of the expected size were obtained in liver and heart from virgin and lactating animals in all experimental conditions. The quantity of the large fragment was increased in virgin animals treated with adrenergic agonists (NE and ISO), whereas in lactating rats this increase was exhibited in continuous suckling, resuckling and adrenergic stimulation (NE and ISO). In MG, this fragment was amplified in cDNAs from resuckled and adrenergic-stimulated lactating animals. 


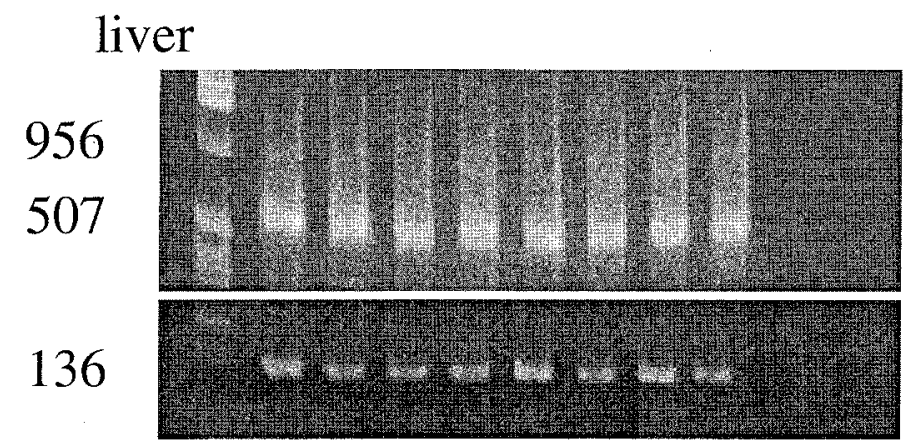

\section{large}

short

As-Bas

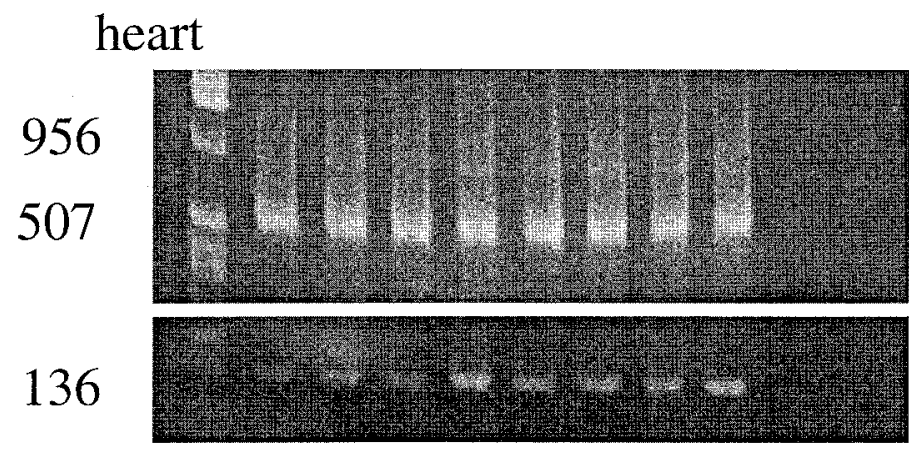

large

short

As-Bas

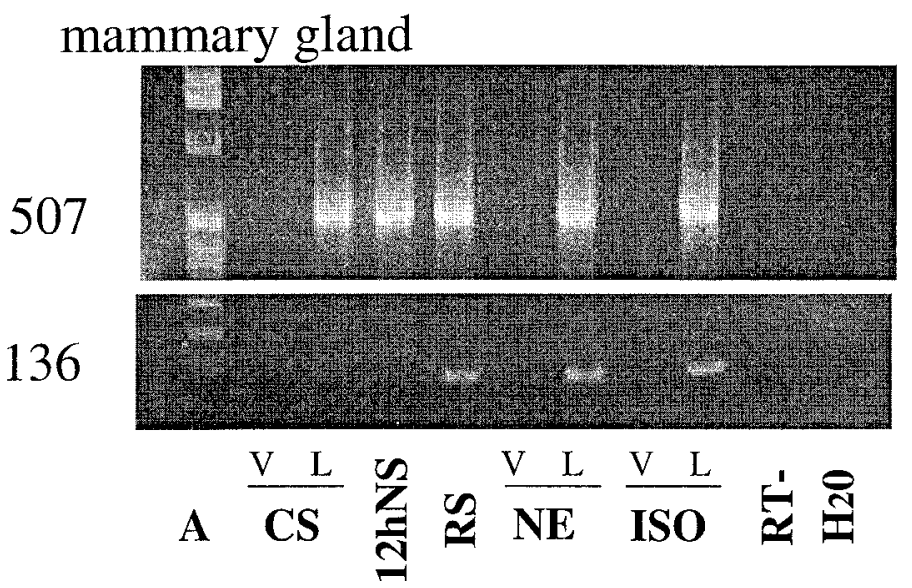

large

short

As-Bas

Figure 4 PCR-RACE amplification of 3'-untranslated region (3'UTR) of D1 mRNAs from virgin (V) and lactating (L) rats (ethidium bromide-stained gel). Oligo(dT) with specific sequence denoted AP (see Fig. 1 and Materials and Methods) was used for RT reactions. In the upper panel, PCR was carried out with complementary sequence oligo(dT), UAP, J3s, and $1 \mu$ l (liver) or $5 \mu \mathrm{l}$ (heart and mammary gland (MG)) aliquots of the RT reaction. In the lower panel, PCR was carried out with oligonucleotides As and Bas, and $1 \mu$ (liver) or $5 \mu \mathrm{l}$ (heart and MG) aliquots of the RT reaction. A, ladder; CS, control animals with continuous suckling; 12 hNS, mothers whose pups were removed for $12 \mathrm{~h}$; RS, mothers whose pups were resuckled after $12 \mathrm{~h}$; NE, animals treated with NE; ISO, animals treated with ISO; RT - , RNA sample and the appropriate oligonucleotide primers, but without reverse transcriptase; $\mathrm{H}_{2} \mathrm{O}$, water with all the PCR reagents. The experiments were repeated twice with independent RNA samples.

\section{Discussion}

The present results confirm and extend our previous analysis of the thyroid-SNS interaction during lactation.
Besides corroborating that lactating rats exhibit an organspecific thyroid hormone-deiodinative rearrangement that resembles hypothyroidism (Valverde-R \& Aceves 1989, Aceves et al. 1994), the present data show for the first time 
that suckling concurrently stimulates heart and MG D1. This simultaneous activation is mediated by $\beta$-adrenergic receptors and suggests that this SNS-D1 interaction is part of a physiological mechanism co-ordinating the metabolic demands imposed by milk production. This notion agrees with previous observations showing that (1) the characteristic homeorhetic adjustments of lactation are modulated by the lactational intensity (litter size, number and frequency of suckling, etc.) (Prentice \& Prentice 1988, Valverde-R \& Aceves 1989); (2) mammary D1 is stimulated in vivo by the NE released in the sympathetic nerve endings (Aceves et al. 1999b); and (3) in the heart, a classic noradrenergic target tissue, lactation increases the $\mathrm{NE}$ turnover rate (Bauman \& Currie 1980).

Although it is well documented that in several organs D2 is regulated by the SNS (Silva 1996, Kohrle 1996, 1999), in the case of D1 the evidence is scarce and contradictory. The possibility of an important effect of catecholamines on extrathyroidal conversion of T4 to T3 was suggested by clinical studies where $\beta$-receptor antagonists decreased the plasma concentration of T3 in thyrotoxic or hypothyroid patients maintained on a fixed dose of T4 (Murchison et al. 1979, Sulkin et al. 1984). Subsequently, in vitro studies in liver and kidney demonstrated that D1 inhibitory effects of propranolol were related to its lipid solubility and not to its $\beta$-adrenergic blocking activity (Heyma et al. 1978, Sulkin et al. 1984). Moreover, when kidney preparations were treated with $\mathrm{NE}$ and $\beta$-agonists, the expected stimulatory D1 response did not appear (Heyma et al. 1980). Besides confirming the lack of $\beta$-adrenergic influence upon liver D1, our findings demonstrate that $\beta$-adrenergic mechanisms do stimulate, in a concerted manner, D1 enzyme in heart and lactating MG. This finding indicates that catecholamines need to be added to the ample variety of regulatory influences known to affect D1 activity in an organ-specific manner; i.e. thyroid status, carbohydrates, selenium, thyrotropin, angiotensin II, cAMP, etc. (Kohrle 1996, Yonemoto et al. 1999, Bates et al. 2000).

As we have mentioned before, rat liver contains two different transcripts of D1 mRNA, and we have shown that the expression of the large form is dependent on thyroid status (Navarro et al. 1997). We now demonstrate that these two mRNA forms are present in all D1containing tissues analyzed herein, and that the larger form is stimulated by resuckling and $\beta$-adrenergic stimulation in heart, but not in liver. Our data also indicate that these stimuli induce the de novo expression of this longer messenger in lactating MG. The physiological role of this differential mRNA expression has not been elucidated; however, studies on other transcripts have demonstrated the involvement of the $3^{\prime} \mathrm{UTR}$ in the control of translation efficiency and/or mRNA stability (Whale \& Keller 1992). Thus, DeSauvage et al. (1992) have shown that amyloid protein, which is expressed by two different transcripts containing two distinct polyadenylated signals, is prefer- entially translated with the large mRNA form. Our results strongly suggest that the large D1 mRNA is preferentially expressed in response to a metabolic overdemand that requires an elevated and rapid supply of local T3 production, i.e. hyperthyroidism, supraphysiological administration of $\beta$-adrenergic agonist or vigorous resuckling after $12 \mathrm{~h}$ of non-suckling. Current studies in our laboratory are exploring the possible differences in translation efficiency and/or stability of these messenger forms, as well as the role of thyroid-SNS interaction on its regulation.

During lactation, adrenergic stimulatory deiodinase response was preserved in predominantly $\beta$-adrenergic receptor-containing tissues (heart and $\mathrm{MG}$ ) and disappeared in tissues (BAT) that contain a mixed population of $\alpha$ - and $\beta_{3}$-adrenergic receptors. These findings coincide with previous reports showing that in a catabolic situation, such as lactation (Giralt et al. 1987, Aceves et al. 1994) or fasting (Silva \& Larsen 1986), the sensibility of D2 BAT to $\mathrm{NE}$ is impaired. The exact mechanism implicated in this differential regulation is unknown; however, several studies suggest that the hormonal and nutritional 'milieu' characteristic of lactation (hypothyroidism, hypoglycemia, hypoinsulinemia, elevated concentrations of growth hormone, etc.) could modulate the adrenergic outflow and response in different target tissues (Silva \& Larsen 1986, Aceves et al. 1994, Larsen \& Berry 1995, Hernandez \& Obregon 2000). Thus, whereas the increased sympathetic tone triggered by suckling may be responsible for maintaining the elevated heart and MG D1 activity observed in the present study, the impaired D2 BAT adrenergic response could be secondary to the accompanying hypothyroidism and the increased growth hormone levels that characterize lactation.

In summary, present results add further support to the notion that, during lactation, peripheral thyronine deiodination represents a functional intersection of the dyad thyroid-SNS. This reciprocal interaction in which suckling plays a major regulatory role subserves the organspecific maintenance of the elevated energy supply in lactating mammary gland.

\section{Acknowledgements}

This work was supported in part by grants PAPIIT IN-227999 from DGAPA/UNAM and 25598 M from CONACyT. We thank Felipe Ortíz Cornejo for animal care and technical assistance, Pilar Galarza for bibliographic assistance, Lourdes Lara for computer advice and Marcela Sanchez for her careful revision of the English version.

\section{References}

Aceves C, Navarro L, Ramirez del Angel A, Luna M \& Valverde-R C 1994 Lactation selectively modifies 5 deiodinative responses to glucose overfeeding. Endocrine 2 547-551. 
Aceves C, Pineda O, Ramírez-CI, Navarro L \& Valverde-R C 1999a Mammary type I deiodinase is dependent on the suckling stimulus: differential role of norepinephrine and prolactin. Endocrinology 140 2948-2953.

Aceves C, Rojas-Huidobro R, Marina N, Morales MT \& Mena F $1999 b$ Mammary gland sympathetic innervation is a major component in type I deiodinase regulation. Endocrine $\mathbf{1 1}$ 115-121.

Bates JM, Spate VL, Morris JS, StGermain DL \& Galton VA 2000 Effects of selenium deficiency on tissue selenium content, deiodinase activity, and thyroid hormone economy in the rat during development. Endocrinology 141 2490-2500.

Bauman DE \& Currie B 1980 Partitioning of nutrients during pregnancy and lactation: a review of mechanisms involving homeostasis and homeorhesis. Journal of Dairy Science $\mathbf{6 3}$ 1514-1529.

DeSauvage F, Kruys V, Marinx O, Huez G \& Octave JN 1992 Alternative polyadenylation of the amyloid protein precursor mRNA regulates translation. EMBO Journal 11 3099-3103.

Giralt M, Iglesias R, Villarroya F \& Mampel T 1987 Changes in liver iodothyronine 5 deiodinase activity during pregnancy and lactation in the rat. Hormone and Metabolism Research 19 510-511.

Hernandez A \& Obregon MJ 2000 Triiodothyronine amplifies the adrenergic stimulation of uncoupling protein expression in rat brown adiposites. American Journal of Physiology, Endocrinology and Metabolism 278 E769-E777.

Heyma P, Larkins RG, Stockigt JR \& Campbell DG 1978 Formation of tri-iodothyronine and reverse tri-iodothyronine from thyroxine in isolated rat renal tubules. Clinical Science and Molecular Medicine $\mathbf{5 5}$ (Suppl.) 567-568.

Heyma P, Larkins RG \& Campbell DG 1980 Inhibition by propranolol of 3,5, $3^{\prime}$-triiodothyronine formation from thyroxine in isolated rat renal tubules: an effect independent of beta-adrenergic blockade. Endocrinology 106 1437-1439.

Kohrle J 1996 Thyroid hormone deiodinases - a selenoenzyme family acting as gate keepers to thyroid hormone action. Acta Medica Austriaca 23 17-30.

Kohrle J 1999 Local activation and inactivation of thyroid hormones: the deiodinase family. Molecular and Cellular Endocrinology 151 103-119.

Larsen PR \& Berry MJ 1995 Nutritional and hormonal regulation of thyroid hormone deiodinases. Annual Review of Nutrition 15 $323-352$.
Larsen PR, Silva JE \& Kaplan MM 1981 Relation between circulating and intracellular thyroid hormones: physiological and clinical implications. Endocrine Reviews 2 87-102.

Leonard JL \& Kohrle J 1996 Intracellular pathways of iodothyronine metabolism. In Werner and Ingbar's The Thyroid: A Fundamental and Clinical Text, edn 7, pp 125-161. Eds LE Braverman \& RD Utiger. Philadelphia: Lippincott-Raven.

Murchison LE, How J \& Bewser PD 1979 Comparison of propranolol and metoprolol in the management of hypothyroidism. British Journal of Clinical Pharmacology 8 581-583.

Navarro L, Landa A, Valverde-R C \& Aceves C 1997 Mammary 5 'deiodinase type I is encoded by a short messenger. Endocrinology $1384248-4254$.

Prentice AM \& Prentice A 1988 Energy cost of lactation. Annual Review of Nutrition 8 63-79.

Silva JR 1996 Catecholamines and the sympathoadrenal system in thyrotoxicosis. In Werner and Ingbar's The Thyroid: A Fundamental and Clinical Text, edn 7, pp 661-670. Eds LE Braverman \& RD Utiger. Philadelphia: Lippincott-Raven.

Silva JE \& Larsen PR 1986 Interrelationship among thyroxine, growth hormone and the sympathetic nervous system in the regulation of 5 -iodothyronine deiodinase in rat brown adipose tissue. Journal of Clinical Investigation 77 1214-1223.

Stolovitzky G \& Cacchi G 1996 Efficiency of cDNA replication in the polymerase chain reaction. PNAS 93 12947-12952.

Sulkin Bl, Peele ME \& Utiger RD 1984 Beta-adrenergic antagonist inhibition of hepatic $3,5,3^{\prime}$-triiodothyronine production. Endocrinology 115 858-861.

Yonemoto T, Nishikawa M, Matsubara H, Mori Y, Toyoda N, Gondou A, Imai Y, Iwasaka T \& Inada M 1999 Type 1 iodothyronine deiodinase in heart. Effect of triiodothyronine and angiotensin II on its activity and mRNA in cultured rat myocytes. Endocrine Journal 46 621-628.

Valverde-R C \& Aceves C 1989 Circulating thyronines and peripheral monodeiodination in lactating rats. Endocrinology 124 1340-1344.

Whale E \& Keller W 1992 The biochemistry of 3' end cleavage and polyadenylation of messenger RNA precursors. Annual Review of Biochemistry 61 419-440.

Received 19 May 2001

Accepted 29 August 2001 